\title{
Deciphering the Scream of Silence: Diagnostic Dilemma of Psychosis in Deaf Mute Patients- A Case Series
}

\author{
Ankit Goel', Sajjadur Rehman ${ }^{2}$, Dinesh Kataria ${ }^{3}$ \\ ${ }^{1}$ Consultant Psychiatrist, The Healthy Mind Clinic, Janakpuri, New Delhi, India. \\ ${ }^{2}$ Specialist, Department of Psychiatry \& Drug De-addiction Center, Lady Hardinge Medical College, New Delhi, India. \\ ${ }^{3}$ Director Professor \& Head of Department, Department of Psychiatry \& Drug De-addiction Center, Lady Hardinge Medical \\ College, New Delhi, India. \\ DOI: https://doi.org/10.24321/2581.5822.202005
}

I $\quad \mathbf{N} \quad \mathbf{F} \quad \mathbf{O}$

Corresponding Author:

Dinesh Kataria, Department of Psychiatry \& Drug De-addiction Center, Lady Hardinge Medical

College, New Delhi, India.

E-mail Id:

drdineshkataria@gmail.com

Orcid Id:

https://orcid.org/0000-0003-4656-2423

How to cite this article:

Goel A, Rehman S, Kataria D. Deciphering the Scream of Silence: Diagnostic Dilemma of Psychosis in Deaf Mute Patients- A Case Series. $J$ Adv Res Psychol Psychother 2020; 3(1): 24-28.

Date of Submission: 2020-01-31

Date of Acceptance: 2020-03-25
$\begin{array}{llllllll}\mathbf{A} & \mathbf{B} & \mathbf{S} & \mathbf{T} & \mathbf{R} & \mathbf{A} & \mathbf{C} & \mathbf{T}\end{array}$

Deaf and mute patients comprise the sub group of population in which assessment and diagnosis of psychotic disorder is challenging. Difficulties in communication is a barrier towards it. Moreover, the patients have varying presentation which makes things even more difficult. In the following three cases, we would discuss the problems faced in assessment of deaf mute patients with possible explanations for it. This may help develop adequate skills and tools for better understanding and management in future of deaf mute patients with psychosis.

Keywords: Psychosis, Deaf Mute, Assessment

\section{Introduction}

Assessment of psychiatric illness in prelingually deaf and mute patients is difficult. Problem in-part is due to the errors created by the cultural and dialectal differences. ${ }^{1}$ One of the major challenges in the assessment of psychosis is that the diagnosis of psychotic disorders is primarily made either by language or observed or self-described behaviour. Language deficits in deaf mute patients and poor training of mental health professionals in sign language pose major hinderance in managing such patients. ${ }^{2}$ The prevalence of psychosis in deaf mute patients vary considerably in various studies. It ranges relatively high in some between $20 \%$ to $54 \%,{ }^{2}$ while in others it is low between $4 \%$ to $8 \%{ }^{3}$ These variations may be due to the factors like difficulty in communicating with deaf mute patients,comorbid organic causes, lack of standardised culturally and linguistically appropriate assessment tools and limited experience of mental health professionals in dealing with deaf and mute pateints.Thus, lack of proper understanding of psychosis in deaf and mute patients creates problems such as wrong diagnosis, longer treatment duration, restricted treatment options as use of psychotherapy becomes difficult. ${ }^{4}$ Moreover, there is a dearth of literature in the assessment and management of psychosis in the deaf mute and the available one is limited by low sample size, methological errors and lack of standardized tools. 
We present three cases of deaf and mute patients presented to us for assessment and management.Each case in itself caused diagnostic challenges due to difficulty in communication, and a lot was interpreted with the information available from the informant coming with the patient. In case 1 , the diagnosis and treatment needed revision in further follow up whereas in other twocases a tentative diagnosis was made and treatment was started.

\section{Case Reports}

\section{Case I}

G, a 24-year-old, non-formally educated, unmarried, unemployed female belongs to six-membered nuclear family and comes from a middle socio-economic urban background presented to psychiatry OPD of a government hospital in central Delhi, with chief complaints of 8 days duration, abrupt onset characterised by irritability, decreased interest in previously enjoyable activities, crying spells, disruptive behaviour, decreased sleep. She was brought to the OPD by her father and younger sister.

She was born full-term vaginal delivery in hospital with uneventful antenatal and perinatal period. She was prelingually deaf and mute since birth. She achieved normal motor and social milestones. She and the family members had developed their own way of communication with hand gestures and sign language.

She was apparently well 8 days back when next day of her elder sister's marriage,the patient appeared sad and interacted less with the family members. She started becoming irritable on small reasons, would start crying and not stop when family members tried to stop her. The next day, when her sister came to visit her she appeared sad and didn't interact with her. Her sleep decreased as she would sleep for 5 hours while previously would sleep 8 hours. She would not take regular baths. Her oral intake had decreased. She was brought to OPD due to unmanageability. Her past history, family and personal history was not contributory. She had well adjusted Premorbid Personality (PMP).Systematic examination was within normal range with no signs of neurological deficits. On Mental Status Examination (MSE), she was appropriate to the stated age, came unaided slowly and sat with erect posture. Eye contact was established but not maintained and working relationship was established. Psychomotor activity was decreased and comprehension was intact. Affect was irritable, reactivity was present, and range was decreased. Patient's elder sister assisted in communication with her by sign language. She expressed not feeling good and would report heaviness in the head. She also cried during the interview for no apparent reason and further didn't participate in the interview. On the basis of history and MSE, a diagnosis of adjustment disorder with predominant disturbance of other emotions (ICD-10, F43.23) was made. On the request of family members, OPD management was started. All blood investigations were sent, and patient was started on tablet escitalopram $10 \mathrm{mg}$ once daily and tablet clonazepam $0.25 \mathrm{mg}$ twice daily. She was brought 1 week later, investigations were within normal range. It was reported that she started becoming fearful and would suspect that family members would discuss about her among themselves and would appear vigilant. She would suspect something mixed in the food while eating her meals. Meanwhile she would be seen smiling, giggling and sometimes crying with no apparent cause. On MSE, the patient was wearing dirty clothes with uncombed hair and dirty nails. Eye contact was established but not maintained and working relationship was established. Psychomotor activity was increased. She appeared vigilant; affect was fearful, restricted and inappropriate. She expressed fearfulness of someone trying to harm her by sign language to her father and sister and her behaviour was characteristically suspicious towards people in her enviornment. On the basis of new information and MSE, diagnosis was revised to other acute and transient psychotic disorders(ICD-10, F23.8). She was started on tablet olanzapine $10 \mathrm{mg}$ with tablet clonazepam $0.5 \mathrm{mg}$ twice daily. On follow up after 2 weeks sleep, appetite and self-care of the patient improved significantly and her fearfulness decreased. She started communicating with the family members as she was doing prior to onset of illness. On being asked about what she remembered about her illness, patient reported with gestures that she was fearful that someone might harm her but at the same time could not tell why she believed so. She is on regular follow up and maintaining well on medications.

\section{Case 2}

S,a 22 year Hindu married female, not formally educated, belonging to a joint family of middle socio-economic rural background presented to psychiatry OPD of a government hospital in central Delhi, with a total duration of illness of 3 years acute onset continuous and progressive course with chief complaints of suspiciousness, irritability of mood, gesticulating behaviours, inappropriate smiling, withdrawn behaviour, decreased sleep and socio-functional decline. She was brought by her father.

Patient was prelingually deaf and mute since birth. She achieved normal motor and social milestones. She would communicate with people with gestures and sign language. She was well adjusted in terms of social and personal functioning when 3 years back patient started having decreased interaction with the family members and taking less part in home activities. She would appear fearful but would not give any reasons. She would appear to be vigilant. This continued for initial 2 months when patient 
would become irritable on minor issues and would even become aggressive at times. She would smile and giggle without reason and when reasoned would become irritable. Patient would stare whenever the family members would talk around her and would even try to know what they are talking and would not be convinced otherwise. She would make gestures in the air as if communicating with someone and when they would ask her she would become irritable or continue to be so. Such instances increased with time and patientat times would make gestures angrily as if arguing with someone even when nobody would be around. Within 6 months of onset,patient would remain to herself, would not take regular bath or brush her teeth andher sleep also decreased. The symptoms further deteriorated and episodes of violence increased. Patient was brought due to unmanageability, was admitted for assessment and management.

Past, family and personal history was not contributory. Systematic examination was within normal range.

Kirby's method for examination of uncooperative patient was applied. Patient was approximate to stated age, came unaided with normal gait, sat with erect posture,wearing dirty, unironed clothes, uncombed hair. She had an irritable behaviour towards the examiner. She was alert and vigilant of the environment. Affect was irritable. She followed initial few simple commands like showing tongue but then became irritable and stopped.

All investigations were within normal range. On the basis of history and MSE, a diagnosis of other non-organic psychotic disorders (ICD-10, F 28) was made and patient was started on tablet olanzapine $5 \mathrm{mg}$, and tablet clonazepam $0.5 \mathrm{mg}$ at bedtime was started. Patient required injection haloperidol $5 \mathrm{mg}$ and injection promethazine $25 \mathrm{mg}$ deep intramuscular in view of violent behavior on the second day of admission. Tablet olanzapine was increased to $10 \mathrm{mg}$ after 1 week. Within one and a half week of starting the medications, there was significant improvement in her sleep, appetite, self care and her aggressive behavior subsided. Patient started interacting with the family members by gestures. She followed up for 3 visits, maintained on tablet olanzapine $10 \mathrm{mg}$ at bedtime. There was significant improvement in the interaction with the doctor treating her. Patient could recollect some of the behaviours like being suspicious of family members. With the help of sign language patient hinted towards noises disturbing her but hallucnations could not be ascertained with accuracy. Currently,she is maintaining well on medications.

\section{Case 3}

R, a 53 year male, Hindu, not formally educated, works as a helper in showroom, married, belongs to a joint family, from a middle socio-economic background in Delhi. Patient was brought to psychiatry OPD of a government hospital in central Delhi by his niece, with total duration of illness of 3 years, acute onset with chief complains of suspiciousness, muttering to self, decreased sleep and decreased self-care.

He was born deaf and mute. He developed a way of communication with his family members and colleagues at work with hand gestures. He adjusted well in personal and social domains and was maintaining well. But 3 years back, patient started suspecting that his wife would mix poison in food to kill him which he would communicate to his niece with gestures.He would not eat the food given by his wife. Within 3 months, patient also started to suspect that the children and sister-in-law were also involved to harm him. He would be seen gesturing as if communicating to someone even when no one would be around. When family members would try to ask whom he was communicating to he would not tell anything. During the course of illness, he stopped going to work as he would even suspect people at work plotting against him. He would try to communicate in sign language which would not be understood by the family members. Such use of signs had never happened before and would lead lo difficulties in communicating with the patient. His sleep, oral intake and self-care decreased. While this continued, his suspiciousness increased in past 1 month when he would even start fighting with the family members and thus was brought to OPD. He had no significant past and personal history. Family history was suggestive of an episode of psychosis in mother 10 years back of abrupt onset of 2 months duration with complete recovery. Patient had a well-adjusted premorbid personality. On MSE, he was appropriate to the stated age, came unaided slowly and sat with erect posture. Eye contact was established and maintained and a working relationship was established. Most of the interview was done with the help of the niece who would translate the questions into sign language and would translate the answers back. He conveyed the mood as being fearful and his affect was anxious, restricted and appropriate. He conveyed the ideas of persecution towards the wife, children, and colleagues and appeared to be convinced despite giving him evidences otherwise. He denied of any perceptual abnormalities although the possibility could not be ruled out as sign language was used. On the basis of history and MSE, a diagnosis of other non-organic psychotic disorders (ICD-10, F 28) was made. He was started on tablet risperidone $2 \mathrm{mg}$ twice daily and tablet clonazepam $0.5 \mathrm{mg}$ at bedtime. Patient followed up after 2 weeks with improvement in sleep, oral intake and self-care. He is maintaining well on medications and on regular follow up and even has joined his work back.

\section{Discussion}

Studies show that psychotic disorders are less diagnosed 
in deaf and mute patients even in specialized psychiatry programs. ${ }^{5}$ Assessment of psychosis is difficult in deaf mute patients and, most commonly, such patients receive diagnosis of psychosis not otherwise specified. ${ }^{6}$

\section{Biography of Psychotic Disorders}

In case 1 , based on initial presentation,a diagnosis of adjustment disorder was retained but later diagnosis of acute psychosis was made. Since the patient was deaf mute, clear phenomenology could not be established and psychosis was established based on symptoms observed by family members. Clear symptoms which were suggestive of psychosis was seen in later part of illness. The initial presentation of symptoms was more suggestive of a depressive illness. It was difficult to think about the possibility of a prodrome at such an early stage. Also inability of proper communication and expression on the part of patient may have resulted in this diagnostic dilemma.

In case 2, diagnosis was reached with the help of history and MSE which was also based on sign language with the help of the attendant. A phenomenon similar to hallucination was seen although this was difficult to establish since the patient was deaf and mute. Similar difficulties are reported in litrature as the notion of hearing voices is confusing to the prelingually deaf and mute patients who have little understanding to the concept of sounds. Infact, eliciting such a phenomenon is difficult even for the interpreter as it has a lot of subjectivity. Interestingly, it is shown that many of the initially appearing hallucinations in psychosis in deaf and mute patients were actually non-hallucinatory experience or born from delusion that one can hear. ${ }^{7}$ Moreover, differences in the structure of a sensory feedback loop is thought to cause differences in the perceptual characteristics of deaf people's voice-hallucinations.This loop relies upon neural connections that are formed by language modality and sensory inputs. ${ }^{8}$ Although a diagnosis of other non-organic psychotic disorders was made but a close differential of schizophrenia (ICD-10, F20) was kept, highliting the barriers to clearly establish the diagnosis in deaf mute patients.

In case 3, initial clinical history and MSE were suggestive of delusion of persecution. An important symptom the patient reported in history was suggestive of thought disorganization conveyed in a non-understandable sign language. But difficulties in language fluency due to language deprivation in deaf mute patients pose a dilemma to differentiate them from thought disorganization. Both conditions can lead to disorganized sign language. Features like disorganized behavior, inappropriate affect may point more towards thought disorganization. ${ }^{9}$ Similar to the above case, diagnosis of other non-organic psychotic disorders was made with possibility of persisitent delusional disorder or schizophrenia.

As with cases above, Bailly et al., 2003 found similar difficulties in diagnosisng psychotic symptoms in deaf mute patients due to language difficulties. They attributed some of the reasons to the procedures being highly language based and not standardized for deaf mute patients. ${ }^{10}$

Deaf and mute patients form a special group of population for assessment of psychiatric symptoms especially psychosis. Many phenomena of psychosis are personal and deficits in language pose difficulties in assessment of deaf and mute group of patients. Hence, much importance should be given on the clinical history from various sources. ${ }^{2}$ As the patients may not be trained in sign language from special educators all the time, clinicians can take help from the family members who are staying with the patient and have an established way of communication through sign language and gestures. Adequate period of observation is necessary as symptoms may take time to evolve. Sleep disturbance, irritability, crying spells and expressing fearfulness were seen in initial phases of psychosis. As illness proceeded, paranoia has started to extend from one object/subject to another with overall deterioration of hygiene and work capacity. Due to issues of difficulty in symptoms' expression and recognition, the duration of untreated psychosis may have extened to years in two cases. Also it is observed, that their response to medication was prompt and good recovery in all the 3 cases.

Mental health professional have limited skills in evaluation and management of psychosis in deaf mute patients which is attributed to poor understanding of sign language and linguistic domains. Such assessment may result in highly subjective inferences leading to a delay in treatment and resource depletion. Establishing special programs for the training of mental health professionals to cater deaf mute population is becoming relevant in recent times.

Lack of standardized diagnostic scales and psychological tests add to the hinderance. Even the modes of management of psychotic disorders in deaf and mute subgroup are limited as use of psychotherapy is difficult. Hence, creation of standardized assessment tools, psychological tests, modifications of psychotherapy and trials of psychopharmacological treatment is increasingly becoming pertinent.

\section{Conclusion}

The case series above shows difficulties in assessning and managing psychotic disorder in deaf and mute patients. In the absence of proper training in sign language of the mental health professional, dearth of psychological assessment tools or module, one has to rely on the family 
members or caregiver who are staying with the patient for communicating and assessment of the patient. Thus, more efforts need to be made in this regard so that the deaf and mute population also get equal opportunity to be assessed, treated and live symptom free life as the rest of the population.

\section{Conflict of Interest: None}

\section{References}

1. Vernon M, Daigle-King B. Historical Overview of Inpatient Care of Mental Patients Who Are Deaf. American Annals of the Deaf 1999; 144(1): 51-61.

2. Landsberger S, Diaz D. Identifying and Assessing Psychosis in Deaf Psychiatric Patients. Current Psychiatry Reports 2011; 13(3): 198-202.

3. Fellinger J, Holzinger D, Schoberberger R, Lenz G. Psychosocial characteristics of deaf people: evaluation of data from a special outpatient clinic for the deaf. Nervenarzt 2005; 76(1): 43-51.

4. Glickman N. Cognitive-behavioral therapy for deaf and hearing persons with language and learning challenges. New York: Routledge; 2009.

5. Vernon M, Daigle-King B. Historical Overview of Inpatient Care of Mental Patients Who Are Deaf. American Annals of the Deaf 1999; 144(1): 51-61.

6. McEntee MK. Accessibility of mental health services and crisis intervention to the deaf. American Annals of the Deaf 1993; 138(1): 26-30.

7. Glickman NS. Do you hear voices? Problems in assessment of mental status in deaf persons with severe language deprivation. J Deaf Stud Deaf Educ 2007; 12: 127-147.

8. Atkinson J. The Perceptual Characteristics of VoiceHallucinations in Deaf People: Insights into the Nature of Subvocal Thought and Sensory Feedback Loops. Schizophrenia Bulletin 2005; 32(4): 701-708.

9. Thacker AJ. Formal communication disorder: Sign language in deaf people with schizophrenia. $\mathrm{Br} \mathrm{J}$ Psychiatry 1994; 165: 818-823.

10. Bailly $D$, de Chouly de lenclave M, Lauwerier L. Hearing impairment and psychopathological disorders in children and adolescents. Review of the recent literature. Encephale 2003; 29(4): 329-337. 